\title{
THE FEATURES OF THE LEGAL REGULATION OF PROCUREMENT FOR THE STATE AND MUNICIPAL NEEDS DURING THE CORONAVIRUS PANDEMIC ${ }^{1}$
}

\author{
Iolanta V. Baltutite \\ Volgograd State University, Volgograd, Russian Federation
}

Introduction: currently, the normal development of the political, economic and legal spheres is significantly affected by the outbreak of the COVID-19 declared a pandemic by the World Health Organization. The epidemic attracted the attention of health professionals and the population around the world, as previously the coronavirus infections in humans did not go beyond the acceptable level of a biological risk. The current events directly related to the pandemic affect all areas of our habitual way of life, its legal component, including the sphere of procurement for the state and municipal needs. Objective: to study the features, positive and negative aspects of the legal regulation of the contract procurement system for the state and municipal needs in the conditions of introduction of innovative management technologies during the coronovirus pandemic. Methods: the methods of systematization, analysis, and comparative law are used. Results: the author analyzed the innovations in procurement for the state and municipal needs in the context of the pandemic; the specifics and features of the development of the system of state and municipal procurement in the paradigm of industry 4.0 during the pandemic are determined; the shortcomings of the current civil law mechanism for protecting the rights of legal entities in the field of procurement for state and municipal needs based on industry 4.0 technologies during the pandemic are identified; identified the possibility of abuse due to the temporary relaxation of the legislation on public procurement; identified the possibility of the legal qualification of the coronavirus as force majeure, the circumstance that makes it impossible to fulfill the obligations; proved that the introduction of the ability to purchase from a single supplier can negatively affect the activities of small and medium-sized enterprises. Conclusions: the innovations in the legal regulation of procurement for the state and municipal needs amid the pandemic in the context of the fourth industrial revolution contain a number of positive aspects: the launch of many digital services; the simplification of the procedure for conducting purchases in the event of force majeure and emergencies; easing the requirements for small and medium-sized businesses; expanding the opportunities to change the term and price of the contract; the changes in the procedure for applying penalties, etc. However, we should not forget about the possible negative consequences of easing the rules of public procurement: the probability of reducing the efficiency and effectiveness of procurement; the appearance of corruption and its manifestations; the abuse at every stage of public procurement; the difficulties in justifying the real impact of the pandemic on the execution of the state order; the ability to purchase from a single supplier can negatively affect the activities of small and medium-sized enterprises; the risk of the violation of antitrust laws due to constantly changing regulations and other consequences.

Key words: contract system, the fourth industrial revolution, public procurement, pandemic, coronavirus, force majeure.

Citation. Baltutite I.V. The Features of the Legal Regulation of Procurement for the State and Municipal Needs During the Coronavirus Pandemic. Legal Concept, 2020, vol. 19, no. 3, pp. 21-30. (in Russian). DOI: 


\title{
ОСОБЕННОСТИ ПРАВОВОГО РЕГУЛИРОВАНИЯ ЗАКУПОК ДЛЯ ГОСУДАРСТВЕННЫХ И МУНИЦИПАЛЬНЫХ НУЖД В ПЕРИОД ПАНДЕМИИ КОРОНАВИРУСНОЙ ИНФЕКЦИИ ${ }^{1}$
}

\author{
Иоланта Видмантовна Балтутите \\ Волгоградский государственный университет, г. Волгоград, Российская Федерация
}

\begin{abstract}
Введение: в настоящее время на нормальное развитие политической, экономической и правовой сферы оказывает существенное влияние вспышка коронавирусного заболевания COVID-19, объявленного Bсемирной организацией здравоохранения пандемией. Эпидемия привлекла к себе внимание специалистов здравоохранения и населения во всем мире, так как ранее коронавирусные инфекции улюдей не выходили за пределы допустимого уровня биологического риска. Происходящие сегодня события, непосредственно связанные с пандемией, затрагивают все сферы привычного уклада жизни, его правовую составляющую, в том числе сферу закупок для государственных и муниципальных нужд. Цель: исследование особенностей, специфики, положительных и негативных сторон правового регулирования контрактной системы закупок для государственных и муниципальных нужд в условиях внедрения инновационных технологий хозяйствования в период пандемии коронавирусной инфекции. Методы: использованы методы системности, анализа и сравнительно-правовой. Результаты: проанализированы нововведения в проведении закупок для государственных и муниципальных нужд в условиях пандемии; определены специфика и особенности развития системы государственных и муниципальных закупок в парадигме индустрии 4.0 в период пандемии; выявлены недостатки действующего гражданско-правового механизма защиты прав субъектов правоотношений в сфере закупок для государственных и муниципальных нужд, основанных на технологиях индустрии 4.0 в период пандемии; установлена возможность злоупотреблений из-за временного послабления законодательства о государственных закупках; определены возможности правовой квалификации коронавируса в качестве непреодолимой силы, обстоятельства, обусловливающего невозможность исполнения обязательств; доказано, что введение возможности закупать у единственного поставщика может отрицательно сказаться на деятельности предприятий малого и среднего звена. Выводы: нововведения в правовом регулировании закупок для государственных и муниципальных нужд в условиях четвертой промышленной революции на фоне пандемии содержат в себе ряд положительных моментов: запуск множества цифровых сервисов; упрощение порядка осуществления закупок при возникновении обстоятельств непреодолимой силы и чрезвычайных ситуаций; смягчение требований для субъектов малого и среднего предпринимательства; расширение возможностей изменения срока и цены контракта; изменения в порядке применения штрафных санкций и др. Однако не нужно забывать и о возможных негативных последствиях смягчения правил государственных закупок: вероятность снижения эффективности и результативности осуществления закупок;возникновение коррупции и ее проявлений; злоупотребления на каждом этапе осуществления государственной закупки; трудности в обосновании реального влияния пандемии на исполнение государственного заказа; возможность закупать у единственного поставщика может отрицательно сказаться на деятельности предприятий малого и среднего звена; риск нарушения антимонопольного законодательства вследствие постоянно меняющегося регулирования и другие последствия.
\end{abstract}

Ключевые слова: контрактная система, четвертая промышленная революция, государственные закупки, пандемия, коронавирус, обстоятельство непреодолимой силы.

Цитирование. Балтутите И. В. Особенности правового регулирования закупок для государственных и муниципальных нужд в период пандемии коронавирусной инфекции // Legal Concept $=$ Правовая парадигма. -2020. - T. 19, № 3. - С. 21-30. - DOI: https://doi.org/10.15688/lc.jvolsu.2020.3.3

\section{Введение}

На сегодняшний день коронавирус COVID-19 внесен в перечень заболеваний, представляющих опасность для здоровья населения. Всемирной организацией здравоохранения вспышка коронавируса COVID-19 объявлена пандемией [8]. Согласно ст. 72 Кон- 
ституции РФ, осуществление мер по борьбе с эпидемиями относится к вопросам совместного ведения РФ и ее субъектов. На основании положений специальных федеральных законов, подзаконных нормативных актов в ряде субъектов РФ было принято решение о введении режима повышенной готовности. Государственная поддержка экономики на фоне эпидемии коронавируса наряду с поддержкой населения стала одной из главных задач российского правительства.

Безусловно, в сложившихся условиях данное заболевание может оказать влияние на многие сферы жизнедеятельности, в том числе и на государственные закупки.

\section{Новые правила регулирования государственных и муниципальных закупок в условиях пандемии}

В условиях угрозы распространения коронавируса стало очевидно, что именно перевод процедур расходования бюджетных средств в электронную форму позволил практически без сбоев проводить как запланированные, так и чрезвычайные конкурентные и неконкурентные закупки. Традиционные способы проведения закупочных процедур все больше отходят на второй план, уступая место электронным закупкам.

До 1 июля 2018 г. лишь один из способов отбора исполнителей проводился в электронной форме - электронный аукцион. Со вступлением в силу изменений в контрактном законодательстве РФ, после 1 июля 2018 г. в электронной форме начали проводиться все открытые закупки, кроме того, в случаях, предусмотренных решением Правительства Российской Федерации, закрытый конкурс, закрытый конкурс с ограниченным участием, закрытый двухэтапный конкурс, закрытый аукцион. Уже с 1 января 2019 г. проведение электронного аукциона стало обязанностью заказчика.

До недавнего времени основным мотивом внедрения цифровых технологий было повышение эффективности закупочной деятельности. Во время пандемии на первое место вышло другое преимущество цифровых технологий - возможность минимизировать физические контакты.
В Письме ФАС России от 5 апреля 2020 г. № ME/28054/20 указывалось, что на период пандемии работа электронных площадок будет обеспечена операторами в обычном режиме. Заказчики и поставщики получили возможность работать дистанционно. Кроме того, одним из первых изменений в связи с пандемией стало предоставление бесплатного доступа к электронному документообороту для клиентов платформ в целях проведения электронных закупочных процедур, которые таким образом смогли продолжить свою деятельность максимально безопасно.

Заказчики не останавливали торги, своевременно появились разъяснения от регуляторов по срокам процедур. Многие электронные площадки запустили новые форматы связи - горячую линию, дополнительную поддержку поставщиков, бесплатные обучающие вебинары об особенностях закупок в условиях чрезвычайной ситуации.

Благодаря уже имеющемуся функционалу площадок был быстро запущен сервис «онлайн-перевыпуск электронной цифровой подписи», при отсутствии возможности лично обратиться в удостоверяющий центр услуга стала крайне востребованной. Кроме того, было организовано дистанционное заседание и голосование членов комиссий с возможностью подписания протоколов электронной подписью.

Торговые площадки обеспечили участников торгов бесплатными онлайн-вебинарами и онлайн-конференциями на самые актуальные темы: закупки медицинских изделий и лекарственных препаратов, импортозамещение, закупки у единственного поставщика, изменения в законодательстве. Онлайн-формат оказался очень популярным и удобным, он позволяет делиться опытом и не ограничиваться рамками регионов.

Участники получили возможность оформить банковскиегарантии в электронном виде. Все коммуникации с банком и оформление такой гарантии проходят через Интернет, а документы подписываются электронной подписью, которая придает документам юридическую силу.

С 2020 г. появилась возможность заполнения электронной формы приемки товаров (работ, услуг). По итогам процедуры электронного актирования приемки с использова- 
нием функциональных возможностей единой информационной системы документы о приемке товаров, подписанные электронной подписью, признаются равнозначными документам на бумажном носителе, подписанным собственноручной подписью [9].

Однако не нужно забывать и о возможных негативных последствиях распространения электронных процедур, поскольку резко возрастет нагрузка на единую информационную систему, что поставит под угрозу своевременное планирование и исполнение контрактов.

При определении правовых последствий, вызванных как самим вирусом, так и мерами по предотвращению его распространения, важным является вопрос: следует ли относить коронавирус к обстоятельствам непреодолимой силы, в том числе для целей применения норм законодательства о государственных закупках.

Министерство финансов Российской Федерации в письме от 19 марта 2020 г. № 24-06-06/21324 «Об осуществлении закупок у единственного поставщика (подрядчика, исполнителя) при введении режима повышенной готовности» указало на то, что «распространение новой коронавирусной инфекции носит чрезвычайный и непредотвратимый характер, в связи с чем является обстоятельством непреодолимой силы» [3].

На этом же настаивает Федеральная антимонопольная служба в письме от 18 марта 2020 г. № ИА/21684/20 [4], обращая внимание на вышеуказанный факт при рассмотрении жалоб, дел об административных правонарушениях, обращений о включении в реестр недобросовестных поставщиков, проведении проверок в сфере закупок.

Национальное законодательство не содержит конкретного указания на признание инфекции, вызванной коронавирусом COVID19, обстоятельством непреодолимой силы, однако п. 3 ст. 401 Гражданского кодекса РФ (далее - ГК РФ) содержит указание на то, что непреодолимой силой являются чрезвычайные и непредотвратимые при данных условиях обстоятельства. При этом перечень обстоятельств непреодолимой силы в законодательстве отсутствует.

Верховный суд РФ высказал позицию о том, что признание распространения но- вой коронавирусной инфекции обстоятельством непреодолимой силы не может быть универсальным для всех категорий должников и ситуаций.

Введенные государством ограничительные меры, вызванные распространением коронавируса, относятся к обстоятельствам непреодолимой силы, и в таких условиях исполнители временно освобождаются от ответственности за нарушения при исполнении обязательств по государственным контрактам на период, когда они не могут их выполнить по объективным причинам.

Если речь идет о неисполнении или ненадлежащем исполнении обязательств по договорам в сфере государственных закупок, то по общему правилу применяется норма п. 3 ст. 401 ГК РФ. В частности, если иное не предусмотрено законодательством или договором, лицо, не исполнившее обязательство либо исполнившее его ненадлежащим образом при осуществлении предпринимательской деятельности, несет ответственность, если не докажет, что надлежащее исполнение обязательства невозможно вследствие непреодолимой силы, то есть чрезвычайных и непредотвратимых при данных условиях обстоятельств.

В этом случае ответственность не наступает при наличии доказанных субъектом хозяйствования обстоятельств непреодолимой силы.

Квалификация события как обстоятельства непреодолимой силы с точки зрения действующего законодательства - это сфера полномочий судебных органов по результатам оценки такого события на наличие у него двух свойств - чрезвычайности и непредотвратимости. В частности, Верховный суд РФ указывает, что в любом случае необходимы соответствие имеющихся обстоятельств критериям непреодолимой силы и наличие причинной связи между этими обстоятельствами и неисполненным обязательством [2].

Ранее Судом были даны разъяснения о том, что наступление обстоятельств непреодолимой силы не прекращает обязательство должника, если его исполнение остается возможным после того, как они отпали (п. 9 Постановления Пленума ВС РФ от 24 марта 2016 г. № 7 «О применении судами некоторых положений Гражданского кодекса Российской 
Федерации об ответственности за нарушение обязательств») [5].

Таким образом, обстоятельства непреодолимой силы могут освободить от ответственности за неисполнение обязательств по договору, но не от их исполнения. Соответственно, обязательства должны соблюдаться с учетом требований законодательства о государственных закупках и исполняться в соответствии с ним. Факт расторжения договора в связи с неисполнением или ненадлежащим исполнением обязательств по договору исполнителем является основанием для его включения в список поставщиков (подрядчиков, исполнителей), временно не допускаемых к участию в процедурах закупок.

Довольно часто судебные споры возникают между хозяйствующими субъектами изза неравного понимания сторонами последовательности, сроков и объема исполнения своих обязательств по поставке товаров, выполнению работ, оказанию услуг, осуществлению имущественных прав, а также из-за различных толкований тех документов, которые стороны составляют при совершении сделок. Огромные материальные и временные ресурсы тратятся на доказывание того или иного обстоятельства, на отстаивание той или иной позиции, вытекающей из толкования стороной своих конкретных обязательств по сделке [12]. В настоящее время в период пандемии ситуация и вовсе осложнится, отрицательно скажется на экономической динамике в целом, навсегда нарушит сложившиеся между хозяйствующими субъектами хозяйственные и договорные отношения.

В конечном итоге только судебная практика покажет, как в целом будут квалифицированы происходящие сейчас события, каким образом, в частности, будут, и будут ли в принципе, применяться положения о коронавирусе как обстоятельстве непреодолимой силы в государственных закупках.

Согласно ГК РФ, основанием для изменения или расторжения договора являются существенные изменения обстоятельств, из которых стороны исходили при заключении договора, если иное не предусмотрено договором или не вытекает из его существа.

Изменение обстоятельств признается существенным, если они изменились настоль- ко, что, если бы стороны могли это разумно предвидеть, договор вообще не был бы ими заключен или был бы заключен на значительно отличающихся условиях.

Для сферы государственных закупок подлежат применению нормы ст. 95 Федерального закона от 5 апреля 2013 г. № 44-Ф3 «О контрактной системе в сфере закупок товаров, работ, услуг для обеспечения государственных и муниципальных нужд» (далее - Закон № 44-Ф3) [11], в частности не допускается изменение условий договора при его исполнении, за исключением случаев, установленных законом.

Однако с 1 апреля 2020 г. вступил в силу Федеральный закон № 98-Ф3 «О внесении изменений в отдельные законодательные акты Российской Федерации по вопросам предупреждения и ликвидации чрезвычайных ситуаций» (далее - Закон № 98-Ф3) [10], которым в части был реформирован Закон № 44-ФЗ.

Согласно нововведениям, стороны могут изменить условия контракта в части срока и/ или цены такого контракта в ходе его исполнения в связи с эпидемией или по другой причине, связанной с распространением коронавируса. Статья 112 Закона № 44-ФЗ была дополнена новой частью 65 , которая устанавливает необходимость подтверждения обстоятельств, на основании которых изменяются условия контракта. В частности, в качестве таких доказательств должны быть предоставлены письменные обоснования и решение исполнительного органа государственной власти (в настоящий момент в качестве такого органа выступает Правительство РФ, а выдачу справок о форс-мажоре осуществляет Торгово-промышленная палата РФ).

Кроме того, вышеуказанным нормативным актом закрепляются следующие положения на период пандемии:

- согласно изменениям в ч. 42.1 ст. 112 Закона № 44-Ф3 с исполнителей будут списаны суммы неустоек и иных штрафных санкций за 2020 г. за неисполнение или ненадлежащее исполнение условий контракта. Законодателем скорректированы правила списания неустойки, утвержденные Постановлением Правительства РФ от 4 июля 2018 г. № 783 [7]. Теперь они устанавливают, в том числе, порядок списания неустойки за неисполнение 
обязательств по контрактам за 2020 г. из-за распространения новой коронавирусной инфекции;

- в рамках измененной ст. 112 Закона

№ 44-ФЗ заказчик в случаях закупки у субъектов малого предпринимательства имеет право отказаться и не требовать от таких участников закупки обеспечения исполнения контракта, гарантийных обязательств. Исключением при этом является предусмотренная договором выплата аванса;

- претерпела изменения ч. 7 ст. 34 Закона № 44-Ф3 в части исчисления пени. В рамках измененных условий, в случае если контрактом предусмотрены этапы работ, пеня будет начисляться из расчета за каждый этап исполнения контракта, то есть от цены соответствующего этапа;

- изменения в ч. 55, 57 ст. 112 Закона № 44-Ф3. С 1 апреля 2020 г. ранее указанные части ст. 112 распространяются не только на закупаемые «под ключ» объекты капитального строительства, реализуемые в рамках национальных проектов, но и на любое предусмотренное проектной документацией оборудование, необходимое для эксплуатации объекта, а не только медицинское, как это было ранее. Перечень таких объектов будет утвержден в срок до 1 января 2024 г.;

- утратили силу ст. 80-82 Закона № 44Ф3, в связи с чем можно говорить об упрощении процедуры закупок в режим чрезвычайной ситуации и других, предусмотренных законом обстоятельств.

Поскольку распространение коронавируса признано обстоятельством непреодолимой силы, заказчики могут осуществлять закупки у единственного поставщика на основании п. 9 ч. 1 ст. 93 Закона № 44-Ф3. В письме № 24-0606/21324 от 19 марта 2020 г. Министерство финансов РФ указало, что заказчики вправе проводить любые закупки, которые требуются в связи с введением режима повышенной готовности, по п. 9 ч. 1 ст. 93 44-Ф3. В письме говорится и о том, в каких регионах введен режим повышенной готовности по коронавирусу в России, а именно во всех 85 субъектах РФ.

Федеральная антимонопольная служба РФ в письме № ИА/21684/20 от 18 марта 2020 г. указала, что для таких закупок в связи с коронавирусом нужна причинно-следственная связь между объектом закупки и профилактикой, предупреждением или ликвидацией последствий распространения коронавирусной инфекции.

Получается, что не на все товары разрешили проводить государственные закупки из-за коронавируса у единственного поставщика, а только на те, которые используются для профилактики, предупреждении или ликвидации последствий распространения коронавирусной инфекции.

До 31 декабря 2020 г. включительно Правительство РФ установило дополнительные случаи осуществления закупок товаров, работ, услуг у единственного поставщика (подрядчика, исполнителя), а также определило порядок осуществления закупок в таких случаях [6].

\section{Выводы}

Стремительное развитие цифровых технологий в мире приводит к интенсивной трансформации всей системы общественных отношений. Технологические изменения требуют большей гибкости и от системы закупок. Существование единой информационной системы закупок, электронных площадок, электронная форма закупок, несомненно, содержат в себе ряд положительных моментов, и именно эти новые технологии в закупках позволили оперативно отреагировать на такое непредсказуемое событие, как пандемия. Пандемия коронавируса стала дополнительным стимулом для реформирования контрактной системы закупок и показала, что нужно сделать, чтобы найти баланс между временем, эффективностью и соблюдением закупочных процедур.

Представляется важным отметить в развитии электронных услуг в период пандемии тенденцию к достижению интеграции экономических и общественных интересов путем использования возможностей новых информационных технологий для удовлетворения потребностей не только отдельных бизнес-структур, но всего общества, предполагающую активное участие государства в хозяйственных и социальных взаимодействиях.

В период пандемии коронавируса и связанных с ней ограничительных мер площадки электронных торгов запустили множество цифровых сервисов. 
Особенностью электронных услуг в рамках контрактной системы является их функциональная направленность на оптимизацию и рациональное использование факторов производства, а именно минимизацию затрат материальных, трудовых, временных ресурсов, создание новых видов деловой активности в электронной среде, борьбу с коррупцией, развитие конкуренции в данной сфере.

Несмотря на положительные тенденции развития правового регулирования государственных закупок в период пандемии, мы можем заметить и негативные стороны вышеуказанных нововведений.

Закрепленная законом необходимость обоснования реального влияния пандемии на конкретную ситуацию при исполнении государственного заказа на практике оказывается трудноосуществимой для исполнителей. Проблематичным остается доказывание возникновения обстоятельств, не позволяющих исполнить контрактные обязательства: отсутствие товаров на рынке, нарушение обязательств со стороны третьих лиц и прочие, которые не являются основаниями для освобождения от ответственности. В действительности они обусловлены именно непредвиденными обстоятельствами в виде пандемии: ежедневно меняющееся регулирование (например, издание актов о срочной закупке учреждениями определенного профиля конкретных товаров) влечет рост спроса на товар, увеличение производственной нагрузки на заводы, затягивание ими сроков выпуска продукции и, как следствие, дефицит на рынке. Однако данные причины не принимаются заказчиками в качестве непредвиденных обстоятельств. Многие из них по-прежнему требуют сертификаты Торговопромышленной палаты РФ, фиксирующей возникновение форс-мажора, притом что данная организация подтверждает обстоятельства непредвиденной силы по внешнеэкономическим сделкам и в существенно долгие сроки. По последним отчетам Торгово-промышленной палаты РФ, более 96 \% обращений за сертификатами остаются без удовлетворения [1].

Закупка у единственного поставщика, по замыслу законодателя, должна устранить временные затраты на длительные процедуры торгов, недопустимые при наступлении форсмажора и введении режима повышенной го- товности. Одновременно такая закупка проходит по универсальным правилам закона: как и любая иная закупка у единственного поставщика, она должна иметь причинно-следственную связь с обстоятельствами, которыми оправдывается. Разрешение государственным заказчикам проводить любые закупки у единственного поставщика, ссылаясь на пандемию коронавируса как обстоятельство непреодолимой силы, может спровоцировать злоупотребления временным послаблением законодательства о государственных закупках.

Конкуренция в закупках и возможность получения государственных контрактов для многих предприятий малого и среднего бизнеса были одной из немногих возможностей получения прибыли. Введение возможности закупать у единственного поставщика может отрицательно сказаться на деятельности таких предприятий. Важно, чтобы все сведения о государственных расходах оставались общедоступными.

Происходящие события и действия законодателя мы сможем оценить лишь тогда, когда начнутся соответствующие судебные разбирательства, в частности по искам об освобождении от ответственности за нарушения договорных обязательств или изменении/paсторжении договора ввиду существенного изменения обстоятельств.

Также особо отметим, что в условиях четвертой промышленной революции на период пандемии система мониторинга, аудита и контроля закупок будет работать не в полной мере. В ближайшем будущем есть вероятность снижения эффективности и результативности осуществления закупок, возникновения коррупции и ее проявлений, а также злоупотреблений на каждом этапе осуществления государственной закупки.

\section{ПРИМЕЧАНИЕ}

${ }^{1}$ Исследование выполнено за счет гранта Российского научного фонда (проект № 20-18-00314).

The work was supported by Russian Science Foundation (project № 20-18-00314).

\section{СПИСОК ЛИТЕРАТУРЫ}

1. В период действия введенных в связи с пандемией ограничительных мер сертификаты и заключе- 
ния о форс-мажоре выдаются бесплатно на всей территории России // Торгово-промышленная палата РФ : [офиц. сайт]. - Электрон. текстовые дан. - Режим доступа: https://tpprf.ru/ru/interaction/experts/comments/ 361031/ (дата обращения: 08.06.2020). - Загл. с экрана.

2. Обзор по отдельным вопросам судебной практики, связанным с применением законодательства и мер по противодействию распространению на территории Российской Федерации новой коронавирусной инфекции (COVID-19) № 1 : (утв. Президиумом Верховного Суда РФ 21 апреля 2020 г.) // Бюллетень Верховного Суда Российской Федерации. -2020 . - № 5 .

3. Письмо Минфина России от 19.03.2020 № 24-06-06/21324 «Об осуществлении закупок у единственного поставщика (подрядчика, исполнителя) при введении режима повышенной готовности». - Электрон. текстовые дан. - Режим доступа: https://www.minfin.ru/ru/document/?id 4=129863pismo_minfina_rossii_ot_19.03.2020 24-06-0621324 ob_osushchestvlenii_zakupok_u_yedinstvennogo_ postavshchika podryadchika ispolnitelya pri_vvedenii rezhima_povyshennoi_gotovn (дата обращения: 08.06.2020). - Загл. с экрана.

4. Письмо Федеральной антимонопольной службы РФ № ИА/21684/20 от 18.03.2020. - Электрон. текстовые дан. - Режим доступа: https:// www.garant.ru/products/ipo/prime/doc/73671379/ (дата обращения: 07.06.2020). - Загл. с экрана.

5. Постановление Пленума Верховного Суда РФ от 24.03.2016 № 7 «О применении судами некоторых положений Гражданского кодекса Российской Федерации об ответственности за нарушение обязательств» // Российская газета. - 2016. - 4 апр. (№ 70).

6. Постановление Правительства РФ от 08.05.2020 № 647 «Об установлении случаев осуществления закупок товаров, работ, услуг для государственных и (или) муниципальных нужд у единственного поставщика (подрядчика, исполнителя) и порядка их осуществления и о внесении изменений в постановление Правительства Российской Федерации от 3 апреля 2020 г. № 443» // Собрание законодательства Российской Федерации. - 2020. № 20. - Ст. 3171.

7. Постановление Правительства РФ от 04.07.2018 г. № 783 «Об осуществлении заказчиком списания сумм неустоек (штрафов, пеней), начисленных поставщику (подрядчику, исполнителю), но не списанных заказчиком в связи с неисполнением или ненадлежащим исполнением в 2015, 2016 и 2020 годах обязательств, предусмотренных контрактом» // Собрание законодательства Российской Федерации. - 2018. - № 28. - Ст. 4242.

8. Романов, Б. К. Коронавирусная инфекция COVID-19 / Б. К. Романов // Безопасность и риск фармакотерапии. - 2020. - № 8 (1). - С. 3-8.
9. Совместное письмо от 18.12.2019 Федерального казначейства № 14-00-06/27476 и ФНС России № AC-4-15/26126@ «Об электронном документообороте документов о приемке товаров (выполнении работ, оказании услуг), сформированным с использованием единой информационной системы в сфере закупок». - Электрон. текстовые дан. Режим доступа: https:/www.referent.ru/40/12901 (дата обращения: 08.06.2020). - Загл. с экрана.

10. Федеральный закон от 1 апреля 2020 года № 98-Ф3 «О внесении изменений в отдельные законодательные акты Российской Федерации по вопросам предупреждения и ликвидации чрезвычайных ситуаций» // Российская газета. - 2020. - 3 апр. (№ 72).

11. Федеральный закон от 05.04.2013 № 44-Ф3 «О контрактной системе в сфере закупок товаров, работ, услуг для обеспечения государственных и муниципальных нужд» // Собрание законодательства Российской Федерации. - 2013. - № 14. Ст. 1652.

12. Kalinina, A. E. Polysubject Jurisdictional Blockchain: Electronic Registration of Facts to Reduce Economic Conflicts / A. E. Kalinina, A. O. Inshakova, A. I. Goncharov // Ubiquitous Computing and the Internet of Things: Prerequisites for the Development of ICT / Ed. E. G. Popkova. - Cham : Springer Science + Business Media, 2019. - P. 205-213. - (Studies in Computational Intelligence; vol. 826.)

\section{REFERENCES}

1. V period deystviya vvedennykh $\mathrm{v}$ svyazi $\mathrm{s}$ pandemiey ogranichitelnykh mer sertifikaty i zaklyucheniya o fors-mazhore vydayutsya besplatno na vsey territorii Rossii [During the Period of Restrictive Measures Imposed in Connection with the Pandemic, Certificates and Opinions on Force Majeure are Issued free of Charge Throughout the Territory of Russia]. Torgovo-promyshlennaya palata $R F$ [Official Website of the Chamber of Commerce and Industry of the Russian Federation]. URL: https://tpprf.ru/ru/ interaction/experts/comments/361031/ (accessed 8 June 2020).

2. Obzor po otdelnym voprosam sudebnoy praktiki, svyazannym s primeneniem zakonodatelstva i mer po protivodeystviyu rasprostraneniyu na territorii Rossiyskoy Federatsii novoy koronavirusnoy infektsii (COVID-19) № 1 (utv. Prezidiumom Verkhovnogo Suda RF 21 aprelya 2020 g.) [Review of Certain Issues of Judicial Practice Related to the Application of Legislation and Measures to Counteract the Spread of a New Coronavirus Infection (COVID-19) No. 1 on the Territory of the Russian Federation. By the Presidium of the Supreme Court of the Russian Federation on April 21,2020) ]. Byulleten Verkhovnogo 
Suda Rossiyskoy Federatsii [Bulletin of the Supreme Court of the Russian Federation], 2020, no. 5.

3. Pismo Minfina Rossii ot 19.03.2020 № 24-0606/21324 «Ob osushchestvlenii zakupok u edinstvennogo postavshchika (podryadchika, ispolnitelya) pri vvedenii rezhima povyshennoy gotovnosti» [Letter of the Ministry of Finance of the Russian Federation of March 19, 2020 No. 24-06-06/21324 "On Procurement from a Single Supplier (Contractor, Performer) when the High-Readiness Mode is Introduced"]. URL: https://www.minfin.ru/ru/document/ ?id_4=129863-pismo_minfina_rossii_ot_19.03.2020_2406-0621324_ob_osushchestvlenii_zakupok_u_ yedinstvennogo_postavshchika_podryadchika_ispolnitelya pri_vvedenii_rezhima_povyshennoi_gotovn (accessed 8 June 2020).

4. Pismo Federalnoy antimonopolnoy sluzhby RF № IA/21684/20 ot 18.03.2020 [Letter of the Federal Antimonopoly Service of the Russian Federation No. IA/21684/20 of March 18, 2020]. URL: https:// www.garant.ru/products/ipo/prime/doc/73671379/ (accessed 7 June 2020).

5. Postanovlenie Plenuma Verkhovnogo Suda RF ot 24.03.2016 № 7 «O primenenii sudami nekotorykh polozheniy Grazhdanskogo kodeksa Rossiyskoy Federatsii ob otvetstvennosti za narushenie obyazatelstv» [Resolution of the Plenum of the Supreme Court of the Russian Federation of March 24, 2016 No. 7 "On the Application by Courts of Certain Provisions of the Civil Code of the Russian Federation on Liability for Breach of Obligations"]. Rossiyskaya gazeta [Russian Newspaper], 2016, 4 apr. (no. 70).

6. Postanovlenie Pravitelstva RF ot 08.05.2020 № 647 «Ob ustanovlenii sluchaev osushchestvleniya zakupok tovarov, rabot, uslug dlya gosudarstvennykh i (ili) munitsipalnykh nuzhd u edinstvennogo postavshchika (podryadchika, ispolnitelya) i poryadka ikh osushchestvleniya i o vnesenii izmeneniy $\mathrm{v}$ postanovlenie Pravitelstva Rossiyskoy Federatsii» [Resolution of the Government of the Russian Federation of May 8, 2020 No. 647 "On Establishing Cases of Procurement of Goods, Works, Services for State and (or) Municipal Needs from a Single Supplier (Contractor, Performer) and the Procedure for Their Implementation and on Amending the Resolution of the Government of the Russian Federation"]. Sobranie zakonodatelstva Rossiyskoy Federatsii [Collection of Legislation of the Russian Federation], 2020, no. 20, art. 3171.

7. Postanovlenie Pravitelstva RF ot 04.07 .2018 g. № 783 «Ob osushchestvlenii zakazchikom spisaniya summ neustoek (shtrafov, peney), nachislennykh postavshchiku (podryadchiku, ispolnitelyu), no ne spisannykh zakazchikom v svyazi s neispolneniem ili nenadlezhashchim ispolneniem v 2015, 2016 i 2020 godakh obyazatelstv, predusmotrennykh kontraktom» [The Resolution of the RF Government of July 4, 2018 No. 783 "About Implementation of Customer Write-Off Amounts of Forfeits (Fines, Penalties) Accrued to the Supplier (Contractor, Artist), but not Deducted by the Customer in Connection with the Failure or Improper Performance in 2015, 2016 and 2020 Obligations Under the Contract"]. Sobranie zakonodatelstva Rossiyskoy Federatsii [Collection of Legislation of the Russian Federation], 2018, no. 28, art. 4242.

8. Romanov B.K. Koronavirusnaya infektsiya COVID-19 [Coronavirus Infection COVID-19]. Bezopasnost i risk farmakoterapii [Safety and Risk of Pharmacotherapy], 2020, no. 8 (1), pp. 3-8.

9. Covmestnoe pismo ot 18.12.2019 Federalnogo kaznacheystva № 14-00-06/27476 i FNS Rossii №AS-4-15/26126@ «Ob elektronnom dokumentooborote dokumentov o priemke tovarov (vypolnenii rabot, okazanii uslug), sformirovannym s ispolzovaniem edinoy informatsionnoy sistemy $v$ sfere zakupok» [Joint Letter Dated 18.12.2019 of the Federal Treasury No. 14-00-06/27476 and the Federal Tax Service of Russia No. AS-4-15/26126@ “On Electronic Document Management of Documents on Acceptance of Goods (Performance of Works, Provision of Services) Formed Using the Unified Information System in the Field of Procurement"]. URL: https://www.referent.ru/ 40/12901 (accessed 8 June 2020).

10. Federalnyy zakon ot 1 aprelya 2020 goda № 98-FZ «O vnesenii izmeneniy v otdelnye zakonodatelnye akty Rossiyskoy Federatsii po voprosam preduprezhdeniya i likvidatsii chrezvychaynykh situatsiy» [Federal Law No. 98-FZ of April 1, 2020 "On Amendments to Certain Legislative Acts of the Russian Federation on Prevention and Liquidation of Emergency Situations"]. Rossiyskaya gazeta [Russian Newspaper], 03.04.2020, no. 72.

11. Federalnyy zakon ot 05.04 .2013 № 44-FZ «O kontraktnoy sisteme v sfere zakupok tovarov, rabot, uslug dlya obespecheniya gosudarstvennykh i munitsipalnykh nuzhd» [Federal Law of April 5, 2013 No. 44-FZ "On the Contract System in the Field of Procurement of Goods, Works, Services for State and Municipal Needs"]. Sobranie zakonodatelstva Rossiyskoy Federatsii [Collection of Legislation of the Russian Federation], 2013, no. 14, art. 1652.

12. Kalinina A.E., Inshakova A.O., Goncharov A.I. Polysubject Jurisdictional Blockchain: Electronic Registration of Facts to Reduce Economic Conflicts. Popkova E.G., ed. Ubiquitous Computing and the Internet of Things: Prerequisites for the Development of ICT. Cham, Springer Science + Business Media, 2019, pp. 205-213. (Studies in Computational Intelligence; vol. 826.). 


\section{Information About the Author}

Iolanta V. Baltutite, Candidate of Sciences (Jurisprudence), Associate Professor, Department of Civil and Private International Law, Base Department of the Southern Scientific Centre of the Russian Academy of Sciences, Volgograd State University, Prosp. Universitetsky, 100, 400062 Volgograd, Russian Federation, u938om@yandex.ru, https://orcid.org/0000-0001-5443-2157

\section{Информация об авторе}

Иоланта Видмантовна Балтутите, кандидат юридических наук, доцент кафедры гражданского и международного частного права (базовая кафедра ЮНЦ РАН), Волгоградский государственный университет, просп. Университетский, 100, 400062 г. Волгоград, Российская Федерация, u938om@yandex.ru, https://orcid.org/0000-0001-5443-2157 